\title{
Electrocardiography versus photoplethysmography in assessment of maternal heart rate variability during labor
}

Hernâni Gonçalves ${ }^{1 *}$, Paula Pinto ${ }^{1,2,3}$, Manuela Silva ${ }^{2}$, Diogo Ayres-de-Campos ${ }^{2,4,5}$ and João Bernardes ${ }^{1,2,4,6}$

\begin{abstract}
Purpose: Evaluation of maternal heart rate (MHR) variability provides useful information on the maternal-fetal clinical state. Electrocardiography (ECG) is the most accurate method to monitor MHR but it may not always be available, and pulse oximetry using photoplethysmography (PPG) can be an alternative. In this study we compared ECG and PPG signals, obtained with conventional fetal monitors, to evaluate signal loss, MHR variability indices, and the ability of the latter to predict fetal acidemia and operative delivery.

Methods: Both signals were simultaneously acquired in 51 term pregnancies during the last $2 \mathrm{~h}$ of labor $\left(\mathrm{H}_{1}\right.$ and $\mathrm{H}_{2}$ ). Linear time- and frequency-domain, and nonlinear MHR variability indices were estimated, and the dataset was divided into normal and acidemic cases, as well as into normal and operative deliveries. Differences between ECG and PPG signals were assessed using non-parametric confidence intervals, hypothesis testing, correlation coefficient and a measure of disagreement. Prediction of fetal acidemia and operative delivery was assessed using areas under the receiver operating characteristic curve (auROC).
\end{abstract}

Results: Signal loss was higher with ECG during the first segments of $\mathrm{H}_{1}$, and higher with PPG in the last segment of $\mathrm{H}_{2}$, and it increased in both signals with labour progression. MHR variability indices were significantly different when acquired with ECG and PPG signals, with low correlation coefficients and high disagreement for entropy and fast oscillation-based indices, and low disagreement for the mean MHR and slow oscillation-based indices. However, both acquisition modes evidenced significant differences between $\mathrm{H}_{1}$ and $\mathrm{H}_{2}$ and comparable auROC values were obtained in the detection of fetal acidemia and operative vaginal delivery.

Conclusion: Although PPG captures the faster oscillations of the MHR signal less well than ECG and is prone to have higher signal loss in the last 10-min preceding delivery, it can be considered an alternative for MHR monitoring during labor, with adaptation of cut-off values for MHR variability indices.

Keywords: Maternal heart rate, Fetal monitoring, Cardiotocography, Signal processing, Electrocardiography, Pulse oximetry

\section{Background}

Computerized analysis of maternal heart rate (MHR) recordings obtained by electrocardiography (ECG) may help in the assessment of different clinical maternalfetal conditions, during the antepartum period (DiPietro

\footnotetext{
*Correspondence: hernanigoncalves@med.up.pt

${ }^{1}$ Center for Health Technology and Services Research (CINTESIS), Faculty of Medicine, University of Porto, Rua Dr Plácido da Costa, $s / n$, 4200-450 Porto, Portugal

Full list of author information is available at the end of the article
}

et al. 2003; Lao et al. 2009; Pinto et al. 2014; Söhnchen et al. 2011; Tejera et al. 2011; Van Leeuwen et al. 2009; Weissman et al. 2009) and in the detection of MHR-fetal heart rate (FHR) ambiguities during labor (Bernardes and Ayres-de-Campos 2012; Hanson 2010; Murray 2004; Sherman et al. 2002).

In clinical practice, however, it is not always possible to obtain MHR recordings with ECG during labour, because many fetal monitors do not incorporate this technology, and some healthcare professionals and laboring women 
think it is unnecessary and interferes with the physiological experience of childbirth. Alternatively, MHR can be obtained with a pulse oximetry sensor and photoplethysmography (PPG), using monitors that have been integrated or are coupled to fetal monitors. Continuous monitoring of maternal oxygen saturation is required in some clinical situations during labor, and some women find it more comfortable than chest electrodes. Moreover, some fetal monitors have recently incorporated pulse oximetry into the tocodynomometer sensor, so MHR can be obtained with no extra equipment. However, there is no data on whether MHR analysis is equivalent when obtained with ECG or PPG.

MHR acquired either by ECG or PPG is transmitted to fetal monitors, which store FHR and MHR simultaneously, typically at a same regular time basis, by means of signal interpolation (STAN Service Manual 2005). However, the heart rate (HR) obtained with PPG is less accurate than that acquired with ECG (Lu and Yang 2009), particularly during exercise (Iyriboz et al. 1991). Similarly, this may also happen in other situations of increased physical effort, namely during labor.

The accuracy of PPG appears to be suitable for the analysis of the HR of newborn infants in the delivery room (Kamlin et al. 2008), in the neonatal intensive care unit (Singh et al. 2008), and in the study of obstructive sleep apnea syndrome, using spectral analysis (Zamarrón et al. 2001) or entropy methods (Hornero et al. 2007), or in the detection of FHR decelerations, in the intrapartum period (Puertas et al. 2005). In addition, artifacts that contaminate PPG waveforms can be automatically rejected using methods based on waveform morphology analysis (Sukor et al. 2011).

To date, no studies have evaluated whether PPG is as accurate as ECG for MHR acquisition during labour. In addition, no studies have compared signal loss when using the two methods.

The objective of this study was to compare simultaneously-acquired ECG and PPG signals for the detection of MHR rate during labour. The following parameters were evaluated in both signals: signal loss, variability indices as evaluators of signal characteristics, and the ability of the latter to predict fetal acidemia and operative delivery. The rationale for MHR to be able to predict fetal acidemia and operative delivery, comes from the knowledge that many situations of fetal hypoxia/acidosis and abnormal labor progression (with its surrogate indicator of operative delivery) are associated with an anomalous pattern of uterine contractions (Ayres-de-Campos et al. 2015), and the latter is related with maternal sympathovagal activity (Kovács et al. 2015; Nagel et al. 2014). MHR variability could thus provide an early sign of fetal academia and/or labour dystocia, by means of the autonomic changes associated with altered uterine contraction dynamics.

\section{Methods \\ Data acquisition}

A total of 51 MHR recordings, pertaining to 51 different laboring women, were obtained simultaneously with ECG and PPG during the last $2 \mathrm{~h}$ before delivery $\left(\mathrm{H}_{1}\right.$ and $\mathrm{H}_{2}$ ). All signals were acquired in uneventful singleton term pregnancies, and all women were under epidural analgesia. The study was approved by the hospital's Ethics Committee ("Parecer no. 19/08, Comissão de Ética para a Saúde do Serviço Regional de Saúde, E.P.E.") and all mothers gave informed consent to participate.

In order to assess the capacity of ECG and PPG signals in the classification of fetal acidemia and operative vaginal delivery, the dataset was divided into normal and acidemic groups-considering an umbilical artery blood (UAB) $\mathrm{pH}$ threshold of 7.15-and into normal and operative vaginal deliveries. The main maternal and perinatal characteristics of the study groups are presented in Table 1.

MHR obtained with ECG was acquired with two unipolar chest electrodes placed on three classical locations (2nd right and left intercostal spaces and 5th left intercostal space in the medioclavicular line) linked to a conventional STAN ${ }^{\circledR} 31$ fetal monitor (Neoventa, Gothemburg, Sweden). The monitor amplifies the signals, digitalises them at a sample rate of $1600 \mathrm{~Hz}$ with a 12-bit precision, and then applies a filter. A heart period is calculated from the RR interval and converted to the nearest integer, in beats per minute (STAN Service Manual 2005).

MHR obtained by PPG was acquired using a conventional pulse oximetry infrared finger probe, linked to the VitalCare 506DN3 Vital Signs Monitor (Criticare Systems, Inc., Wisconsin, USA), which was connected to the STAN $^{\circledR} 31$ fetal monitor. The HR period is derived from analysis of the dual wavelength LED waves, representing arterial blood volume changes, and is transmitted to the fetal monitor at a sampling rate of $1 \mathrm{~Hz}$ with an accuracy and resolution of $\pm 1 \mathrm{bpm}$ (Criticare Systems, Inc. 2009).

Both ECG and PPG signals were exported from the STAN monitor at a sampling rate of $4 \mathrm{~Hz}$, via its RS232 port, into the Omniview-SisPorto ${ }^{\circledR} 3.5$ program (Speculum, Lisbon, Portugal) for storage and subsequent offline analysis. After the application of a pre-processing algorithm described by Gonçalves et al. (2006a), with an adaptation to scale, the signals were resampled at a frequency of $2 \mathrm{~Hz}$ considering only the odd samples, which mitigates the repetition of MHR values, keeping them below the Nyquist frequency (the spectrum of interest is $\leq 0.4 \mathrm{~Hz}$ ). Figure 1 displays an example of MHR signals simultaneously acquired by ECG and PPG, where 
Table 1 Main maternal and perinatal characteristics of the study population, with the subdivisions into normal versus acidemic groups, and normal versus operative vaginal deliveries

\begin{tabular}{|c|c|c|c|c|c|c|}
\hline & $\begin{array}{l}\text { Fetuses born with UAB } \\
\mathrm{pH} \geq 7.15(\mathrm{n}=45)\end{array}$ & $\begin{array}{l}\text { Fetuses born with UAB } \\
\mathrm{pH}<7.15(\mathrm{n}=6)\end{array}$ & p-value & $\begin{array}{l}\text { Normal deliveries } \\
(n=28)\end{array}$ & $\begin{array}{l}\text { Vaginal operative } \\
\text { deliveries }(n=19)\end{array}$ & $p$-value \\
\hline \multicolumn{7}{|c|}{ Maternal data, median (IQR) } \\
\hline Age (years) & $28(3.5)$ & $27(10)$ & 0.597 & $28(8.0)$ & $28(9.0)$ & 0.550 \\
\hline Parity & $0(1)$ & $0(1)$ & 0.853 & $0(1)$ & $0(0)$ & 0.001 \\
\hline $\begin{array}{l}\text { Gestational age } \\
\text { (weeks) }\end{array}$ & $39.9(1.3)$ & $39.8(2.5)$ & 0.578 & $39.7(1.1)$ & $39.9(1.1)$ & 0.415 \\
\hline Delivery, n (\%) & & & 0.693 & & & - \\
\hline Vaginal, normal & $25(56 \%)$ & $3(50 \%)$ & & - & - & \\
\hline Vaginal, operative & $17(37 \%)$ & $2(33 \%)$ & & - & - & \\
\hline Cesarean section & $3(7 \%)$ & $1(17 \%)$ & & - & - & \\
\hline Epidural analgesia, n (\%) & 45 (100 \%) & $6(100 \%)$ & - & $28(100 \%)$ & $19(100 \%)$ & - \\
\hline \multicolumn{7}{|l|}{$\begin{array}{l}\text { Newborn data, median } \\
\text { (IQR) }\end{array}$} \\
\hline Birthweight (g) & $3190(393)$ & $3078(381)$ & 0.255 & $3160(350)$ & $3200(405)$ & 0.871 \\
\hline 1 min Apgar score & $9(1)$ & $9(0)$ & 0.679 & $9(1)$ & $9(1)$ & 0.957 \\
\hline 5 min Apgar score & $10(0)$ & $10(0)$ & 0.679 & $10(0)$ & $10(0)$ & 0.687 \\
\hline UAB pH & $7.27(0.09)$ & $7.10(0.06)$ & 0.000 & $7.27(0.10)$ & $7.22(0.09)$ & 0.109 \\
\hline Gender, n (\%) & & & 0.191 & & & 0.246 \\
\hline Males & $24(53 \%)$ & $1(17 \%)$ & & $11(39 \%)$ & $11(58 \%)$ & \\
\hline Females & $21(47 \%)$ & 5 (83 \%) & & 17 (61 \%) & $8(42 \%)$ & \\
\hline
\end{tabular}

Values within brackets in the header correspond to the number of cases p-value $<0.05$ is in italic

it is patent that the PPG signal smoothens the abrupt oscillations occurring in very short time periods, and thus delays baseline shifts, although this is compensated afterwards.

\section{MHR analysis}

MHR recordings were evaluated using linear (time- and frequency-domain) and nonlinear methods, applied to 10-min segments. The segment-based analysis mitigates the possible effect of non-stationarity. Segments with more than $15 \%$ signal loss (the percentage of MHR values equal to 0) before the pre-processing operation, in one or both of the acquisition modes (ECG or PPG), were excluded from MHR variability analysis.

For time domain linear analysis, the following indices were calculated: mean MHR (mHR); standard deviation of MHR (sdHR); long-term irregularity index, assessed by the inter-quartile range of the squared root of the sum of consecutive pairs of squared samples (LTI); Delta MHR representing the average amplitude within a minute $(\Delta)$; short-term variation (STV); and interval index (II). All but II reflect gross changes in MHR average and variability, whereas II assesses short-term MHR variability taking into account long-term variability (Gonçalves et al. 2006a). For frequency domain analysis, the following frequency bands were considered: very low frequency
(VLF) at $0-0.04 \mathrm{~Hz}$, low frequency (LF) at $0.04-0.15 \mathrm{~Hz}$ and high frequency (HF) at $0.15-0.40 \mathrm{~Hz}$ (Task force of the European Society of Cardiology, the North American Society of Pacing and Electrophysiology 1996). Nonparametric spectrum estimation was performed according to a procedure previously described in detail (Gonçalves et al. 2006a). The whole spectrum area corresponds to the total power (TP). The VLF band appears to reflect thermoregulatory and slow regulating systems of peripheral vessels (Task force of the European Society of Cardiology, the North American Society of Pacing and Electrophysiology 1996) and occurs prominently when autonomic activity is strongly suppressed. LF is associated with the activity of both the sympathetic and parasympathetic branches of the autonomic nervous system, whereas HF is mainly associated with the parasympathetic branch. $\mathrm{LF}_{\text {norm }}$ and $\mathrm{HF}_{\text {norm }}$ were also computed by normalizing each absolute value by TP-VLF. The LF/HF index, which reflects the balance between the autonomic nervous system branches, was also considered.

For non-linear analysis, approximate entropy (ApEn) (Pincus 1991), and sample entropy (SampEn) (Richman and Moorman 2000) were calculated, considering values 0.1 SD, 0.15 SD and 0.2 SD for $\mathrm{r}$ and value 2 for $\mathrm{m}$ (Pincus and Viscarello 1992), while $\mathrm{N}$ was 1200 points (corresponding to 10-min MHR segments). The criterion for 

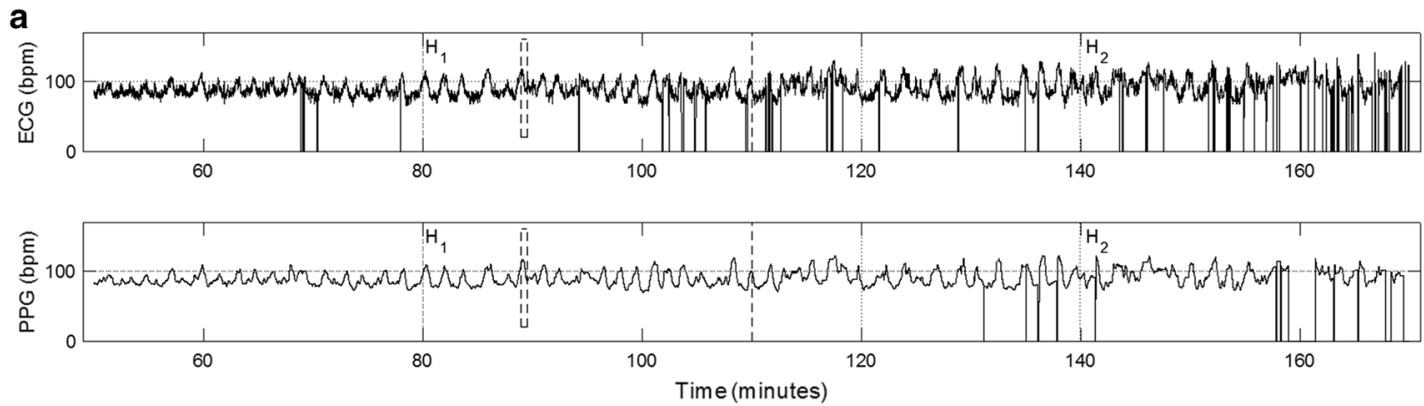

b

MHR obtained from ECG $(x)$ and PPG (o): $4 \mathrm{~Hz}$
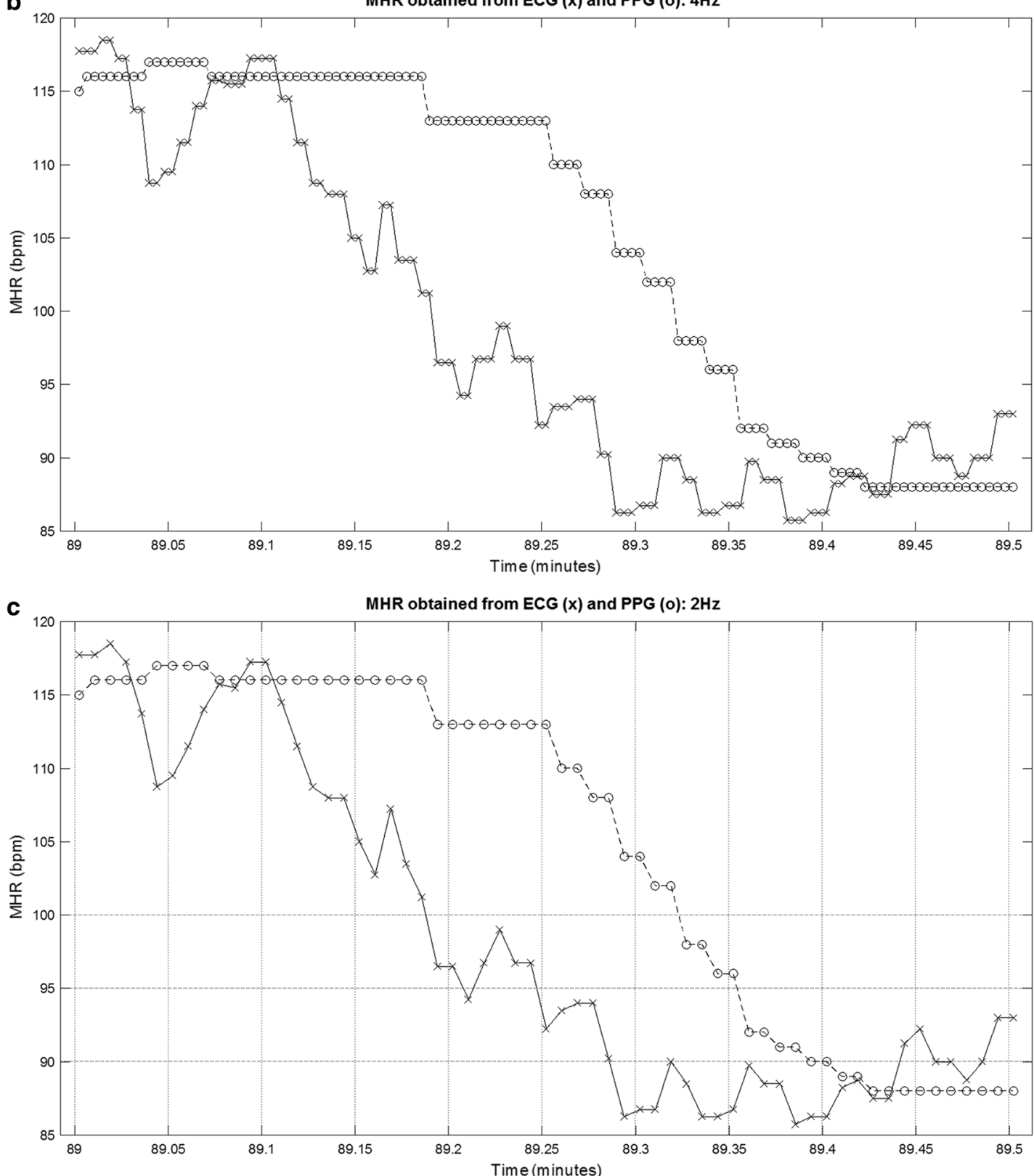

Fig. 1 An example of a MHR tracing obtained with ECG (upper plot) and PPG (lower plot) for $\mathrm{H}_{1}$ and $\mathrm{H}_{2}$ (a). The rectangle between vertical dashed lines in a represents the 30-s segment shown in $\mathbf{b}$ and $\mathbf{c}$, obtained respectively at 4 and $2 \mathrm{~Hz}$ sampling rates, with ECG (marked with a cross) or PPG (marked with a circle) signals 
selection of the threshold parameter $\mathrm{r}$ proposed by $\mathrm{Lu}$ et al. (2008) was also considered. Entropy indices have been associated with complex cortical nervous system activity (Pincus and Viscarello 1992). The Poincaré plot is one of the most popular techniques for analysis of heart rate variability (HRV) (Acharya et al. 2006). It is formed from the representation of each $R R$ interval against its previous RR interval. The most commonly used HR variability indices based on the Poincaré plot are SD1, SD2, and the ratio SD1/SD2, where SD1 and SD2 are related to fast beat-to-beat and longer-term variability, respectively (Acharya et al. 2006). These three nonlinear measures were also considered, and the Poincaré plot was constructed.

\section{Statistical analysis}

The ECG and PPG signals were compared by evaluating the percentage of signal loss, the percentage of MHR values obtained from ECG and PPG differing less than or equal to $5 \mathrm{bpm}\left(\mathrm{HR}_{\mathrm{m}}\right)$ (Behar et al. 2014; Association for the Advancement of Medical Instrumentation 2002) and the previously described MHR variability indices in the six 10-min segments of $\mathrm{H}_{1}$ and $\mathrm{H}_{2}$. Statistical inference was based on $95 \%$ bootstrap $(\mathrm{B}=1000)$ percentile confidence intervals for the median, Spearman correlation of coefficient and nonparametric Mann-Whitney statistical test with significance level set at $\mathrm{p}<0.05$ (Dudewicz and Mishra 1998; Martinez and Martinez 2002). Disagreement was assessed through the information-based approach dAB (Costa-Santos et al. 2010), ranging between 0 and 1 (from lowest to highest disagreement). The ability of each MHR variability index to predict newborn acidemia and operative vaginal delivery was determined using areas under receiver operating curve (auROC).

\section{Results}

The percentage of MHR signal loss for the ECG and PPG signals increased as labor progressed, from $\mathrm{H}_{1}$ to $\mathrm{H}_{2}$, as displayed in Fig. 2. Median signal loss with ECG was significantly higher than with PPG in the first four segments of $\mathrm{H}_{1}$ ( 1 vs $\left.0 \%\right)$, exhibiting a pronounced positively skewed distribution (Fig. 2). Median signal loss with PPG was significantly higher than with ECG in the last segment of $\mathrm{H}_{2}(10 \mathrm{vs} 20 \%)$. A total of 38 out of 306 segments in $\mathrm{H}_{1}(12.4 \%)$ and 113 out of 306 segments in $\mathrm{H}_{2}(36.9 \%)$ were excluded hereafter from analysis due to signal loss higher than $15 \%$ in ECG and/or PPG signals (Fig. 2). MHR values differing less than or equal to $5 \mathrm{bpm}$ between ECG and PPG signals $\left(\mathrm{HR}_{\mathrm{m}}\right)$, had a median of $76.4 \%$ (inter-quartile range of $17.5 \%$ ) in $\mathrm{H}_{1}$, and $71.5 \%$ (inter-quartile range of $22.6 \%$ ) in $\mathrm{H}_{2}$. An episode with differences higher than $5 \mathrm{bpm}$ can be observed in Fig. 1.

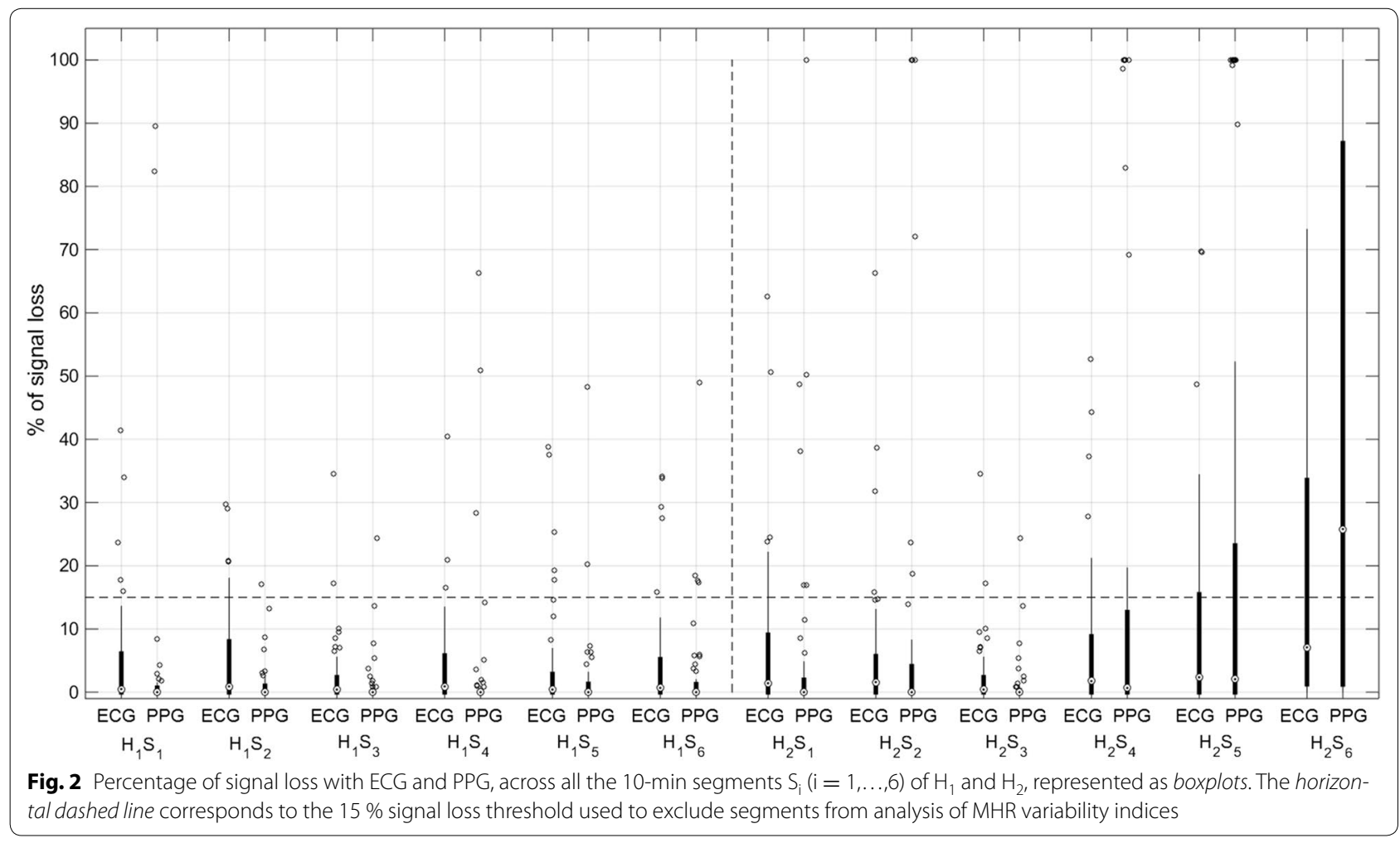


MHR variability indices obtained from PPG signals were significantly lower than those obtained from ECG signals, with the exception of $L F_{\text {norm }}$ and LF/HF (Table 2). The lower values of short-term variability and entropy indices are likely to be due to the inability of PPG to capture faster signal oscillations, as showed in Fig. 1. Most linear indices and $\mathrm{SD}_{2}$ obtained with the two methods were highly correlated, with values ranging between 0.60 and 1.00 , whereas $\mathrm{LF}_{\text {norm }}, \mathrm{HF}_{\text {norm }}, \mathrm{LF} / \mathrm{HF}$ and the remaining non-linear indices had lower correlations, ranging between 0.07 and 0.59 (Table 2).

Progression of labor (from $\mathrm{H}_{1}$ to $\mathrm{H}_{2}$ ) was associated with a significant increase in $\mathrm{SD}_{1}, \mathrm{SD}_{2}$ and most linear indices (excluding II, $\mathrm{LF}_{\text {norm }}, \mathrm{HF}_{\text {norm }}$ and $\mathrm{LF} / \mathrm{HF}$ ) and with a decrease in entropy indices (Table 2). This was generally observed with both acquisition modes, with the exception of most entropy-based indices in PPG signals.
MHR indices related with short-term variability or faster oscillations had the highest disagreements between ECG and PPG recording modes, namely the linear time-domain indices Delta, STV and II, the linear frequency-domain indices, excluding VLF, and the non-linear indices, excluding $\mathrm{SD}_{2}$, for which $\mathrm{d}_{\mathrm{AB}}$ was in the range 0.57-0.96 (Fig. 3).

Considering the analysis of normal versus acidemic newborns, MHR variability indices obtained with ECG or PPG were not significantly different between both groups in $\mathrm{H}_{1}$. However, there were significant differences in $\mathrm{H}_{2}$, both with ECG and with PPG. The highest auROC values were obtained with $\operatorname{SampEn}(2,0.1)$ in $\mathrm{H}_{2}$, with similar auROC values of 0.70 for ECG and PPG (Fig. 4).

There were also significant differences between normal and vaginal operative deliveries in several MHR indices in $\mathrm{H}_{1}$ and $\mathrm{H}_{2}$, both with ECG and PPG signals. The highest auROC value was 0.74 , obtained with $\mathrm{mHR}$ in $\mathrm{H}_{2}$ for ECG and PPG (Fig. 4).

Table 2 MHR variability indices, obtained with ECG and PPG in $\mathrm{H}_{1}$ and $\mathrm{H}_{2}$, presented as $95 \%$ confidence intervals (95\% $\mathrm{Cl})$, with the corresponding p-values and correlation coefficient

\begin{tabular}{|c|c|c|c|c|c|c|c|c|c|c|}
\hline & \multicolumn{4}{|l|}{$\mathrm{H}_{1}$} & \multicolumn{4}{|l|}{$\mathrm{H}_{2}$} & \multirow{2}{*}{\multicolumn{2}{|c|}{$\frac{\mathrm{H}_{1} \text { vs } \mathrm{H}_{2}}{\mathrm{p}}$}} \\
\hline & \multicolumn{2}{|l|}{$95 \% \mathrm{Cl}$} & \multirow[t]{2}{*}{$p$} & \multirow[t]{2}{*}{$r$} & \multicolumn{2}{|l|}{$95 \% \mathrm{Cl}$} & \multirow[t]{2}{*}{$p$} & \multirow[t]{2}{*}{$r$} & & \\
\hline & ECG & PPG & & & ECG & PPG & & & ECG & PPG \\
\hline $\mathrm{mHR}$ & $83.09-85.59$ & $83.19-85.64$ & 0.002 & 1.00 & $86.29-93.13$ & $86.64-93.32$ & 0.016 & 0.99 & 0.000 & 0.001 \\
\hline $\mathrm{sdHR}$ & $5.99-6.55$ & $4.35-5.11$ & 0.000 & 0.90 & $6.66-7.97$ & $5.11-5.99$ & 0.000 & 0.92 & 0.000 & 0.000 \\
\hline LTI & $10.53-11.67$ & $8.13-9.19$ & 0.000 & 0.92 & $12.37-14.33$ & $9.19-11.31$ & 0.000 & 0.90 & 0.000 & 0.000 \\
\hline Delta & $21.42-23.33$ & $10.16-11.44$ & 0.000 & 0.71 & $24.19-27.13$ & $11.30-13.78$ & 0.000 & 0.81 & 0.000 & 0.000 \\
\hline STV & $3.53-3.89$ & $0.94-1.03$ & 0.000 & 0.60 & $3.85-4.41$ & $1.05-1.18$ & 0.000 & 0.71 & 0.001 & 0.000 \\
\hline ॥ & $0.56-0.63$ & $0.19-0.21$ & 0.000 & 0.74 & $0.55-0.60$ & $0.18-0.21$ & 0.000 & 0.72 & 0.177 & 0.573 \\
\hline TP & $25.82-30.27$ & $11.42-14.32$ & 0.000 & 0.83 & $33.50-44.59$ & $14.05-21.23$ & 0.000 & 0.89 & 0.000 & 0.000 \\
\hline VLF & $8.53-10.57$ & 7.53-9.49 & 0.000 & 0.95 & $11.13-15.57$ & $8.88-13.56$ & 0.000 & 0.94 & 0.000 & 0.001 \\
\hline LF & $6.67-8.12$ & $3.20-4.01$ & 0.000 & 0.88 & $8.16-10.87$ & $4.14-5.47$ & 0.000 & 0.90 & 0.000 & 0.000 \\
\hline LF norm & $45.28-50.38$ & $90.90-92.56$ & 0.000 & 0.44 & 43.29-49.99 & $91.69-92.76$ & 0.000 & 0.41 & 0.926 & 0.643 \\
\hline $\mathrm{HF}$ & $4.70-5.61$ & $0.16-0.20$ & 0.000 & 0.71 & $5.90-7.69$ & $0.21-0.27$ & 0.000 & 0.73 & 0.000 & 0.000 \\
\hline${ }^{H F}$ norm & $28.33-32.18$ & $4.70-5.49$ & 0.000 & 0.45 & $28.03-32.48$ & $4.66-5.55$ & 0.000 & 0.45 & 0.805 & 0.958 \\
\hline LF/HF & $1.47-1.69$ & $16.67-19.56$ & 0.000 & 0.48 & $1.35-1.67$ & $16.48-19.73$ & 0.000 & 0.46 & 0.944 & 0.981 \\
\hline $\operatorname{ApEn}(2,0.1)$ & $1.21-1.24$ & $0.55-0.60$ & 0.000 & 0.23 & $1.16-1.21$ & $0.57-0.61$ & 0.000 & 0.22 & 0.010 & 0.276 \\
\hline ApEn $(2,0.15)$ & $1.15-1.20$ & $0.52-0.56$ & 0.000 & 0.43 & $1.10-1.15$ & $0.48-0.56$ & 0.000 & 0.47 & 0.023 & 0.371 \\
\hline ApEn $(2,0.2)$ & $0.98-1.04$ & $0.26-0.45$ & 0.000 & 0.51 & $0.96-1.02$ & $0.24-0.34$ & 0.000 & 0.53 & 0.163 & 0.620 \\
\hline SampEn $(2,0.1)$ & $1.52-1.62$ & $0.38-0.45$ & 0.000 & 0.38 & $1.41-1.54$ & $0.40-0.46$ & 0.000 & 0.59 & 0.039 & 0.524 \\
\hline SampEn $(2,0.15)$ & $1.16-1.29$ & $0.33-0.39$ & 0.000 & 0.38 & $1.06-1.16$ & $0.31-0.38$ & 0.000 & 0.46 & 0.001 & 0.336 \\
\hline SampEn $(2,0.2)$ & $0.91-0.99$ & $0.20-0.28$ & 0.000 & 0.51 & $0.87-0.96$ & $0.18-0.22$ & 0.000 & 0.58 & 0.062 & 0.479 \\
\hline rLu & $0.13-0.13$ & $0.06-0.06$ & 0.000 & 0.48 & $0.12-0.13$ & $0.06-0.06$ & 0.000 & 0.36 & 0.074 & 0.286 \\
\hline $\operatorname{ApEn}(2, \mathrm{rLu})$ & $1.20-1.24$ & $0.57-0.61$ & 0.000 & 0.18 & $1.15-1.21$ & $0.60-0.63$ & 0.000 & 0.12 & 0.007 & 0.003 \\
\hline SampEn $\left(2, r_{L u}\right)$ & $1.33-1.39$ & $0.40-0.46$ & 0.000 & 0.08 & $1.22-1.32$ & $0.43-0.49$ & 0.000 & 0.07 & 0.000 & 0.052 \\
\hline SD1 & $1.57-1.74$ & $0.37-0.39$ & 0.000 & 0.47 & $1.68-2.17$ & $0.40-0.46$ & 0.000 & 0.44 & 0.004 & 0.000 \\
\hline SD2 & $8.21-9.06$ & $6.13-7.22$ & 0.000 & 0.91 & $9.17-10.94$ & $7.21-8.46$ & 0.000 & 0.93 & 0.000 & 0.000 \\
\hline SD1/SD2 & $0.19-0.21$ & $0.06-0.06$ & 0.000 & 0.48 & $0.17-0.19$ & $0.05-0.06$ & 0.000 & 0.36 & 0.078 & 0.308 \\
\hline
\end{tabular}

The last two columns display the $\mathrm{p}$-values of the comparison between $\mathrm{H}_{1}$ and $\mathrm{H}_{2}$ $p$-values $<0.05$ are in italics 

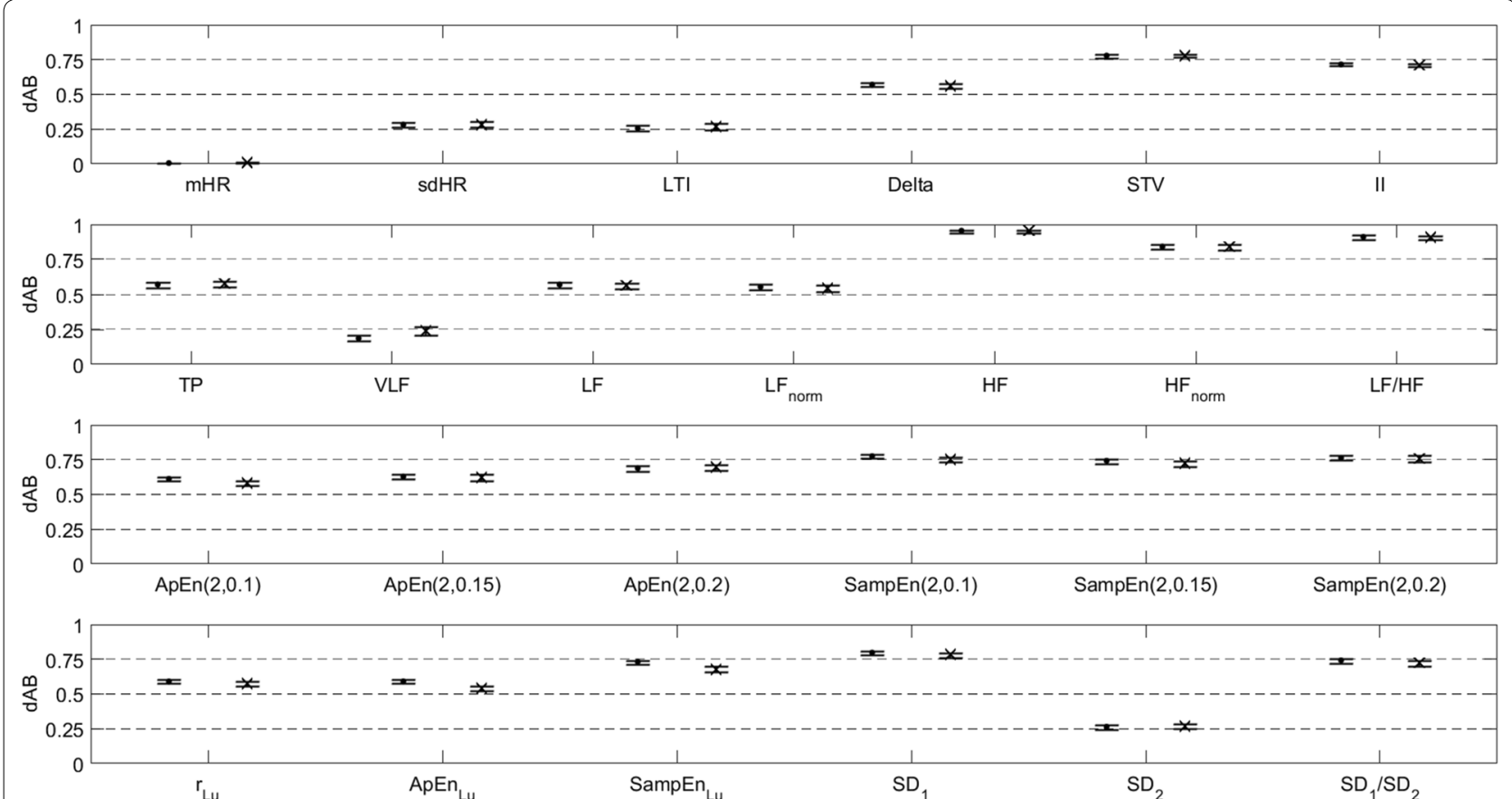

Fig. 3 Disagreement $\left(d_{A B}\right)$ between the MHR variability indices obtained with ECG and PPG, for linear time-domain indices (first row), linear frequency-domain indices (second row), entropy indices (third row) and Poincaré plot indices (fourth row). Disagreement was assessed for the initial $\left(\mathrm{H}_{1}\right.$, dot) and final $\left(\mathrm{H}_{2}\right.$, cross) 10-min tracing segments (error bars represent the $\left.95 \% \mathrm{Cl}\right)$. Note that the zero value corresponds to the minimum disagreement (maximum agreement)

\section{Discussion}

To our knowledge, this is the first study to compare linear and non-linear MHR variability indices obtained with ECG and PPG during labor. The main objective was to determine whether PPG can be used as an alternative to ECG, as the latter may not always be available.

The clinical scenarios chosen to perform our comparison between MHR variability indices derived from signals obtained with ECG or PPG were progression of labor, fetal acidemia and operative vaginal delivery, as these are conditions related with different maternal balances between cortical and autonomic nervous system activities (Tejera et al. 2011; Task force of the European Society of Cardiology, the North American Society of Pacing and Electrophysiology 1996).

The percentage of signal loss with the PPG signal was similar to that of the ECG during the final segments of labour, and was only significantly higher in the last 10-min segment $\left(\mathrm{S}_{6}\right)$ of $\mathrm{H}_{2}$. This may have happened because of maternal movements and inadvertent temporary removal of the pulse oximeter in this more stressful period. In addition, the percentage of signal loss of the PPG signal was significantly lower than the ECG in the first four segments of $\mathrm{H}_{1}$. Therefore, the use of PPG is not compromised because of signal loss in the last $2 \mathrm{~h}$ before delivery, with the exception of the final 10-min segment.
The similarity of MHR variability indices calculated with ECG and PPG signals was not the same for all indices. Those related with faster oscillations and entropy were poorly correlated and exhibited high disagreement. Linear indices related with baseline and long-term variability (e.g. mHR, VLF and $\mathrm{SD}_{2}$ ) were highly correlated and had low disagreement. These findings corroborate the different visible characteristics of the ECG and PPG signals (Fig. 1).

Visual analysis of the PPG signal suggests an absence of the high frequency component, supported by considerably lower absolute values of HF than the ECG signal. Although to a lesser extent, TP, VLF and LF indices derived from the PPG signal were also lower than their ECG counterparts. $\mathrm{LF}_{\text {norm }}$ was approximately twice, $\mathrm{HF}_{\text {norm }}$ was smaller to a larger extent and LF/HF was much higher in PPG signals. In spite of this, a consistent trend from $\mathrm{H}_{1}$ to $\mathrm{H}_{2}$ was observed with both ECG and PPG signals (Table 2). We can therefore conclude that, although spectral indices derived from the two signals are significantly different, if appropriate reference ranges are used, PPG signals may be used as an alternative to the ECG for traditional HRV spectral analysis.

A possible explanation for the difference between ECG and PPG signals is related with the HR extraction technique. A beat detection approach is usually employed in 

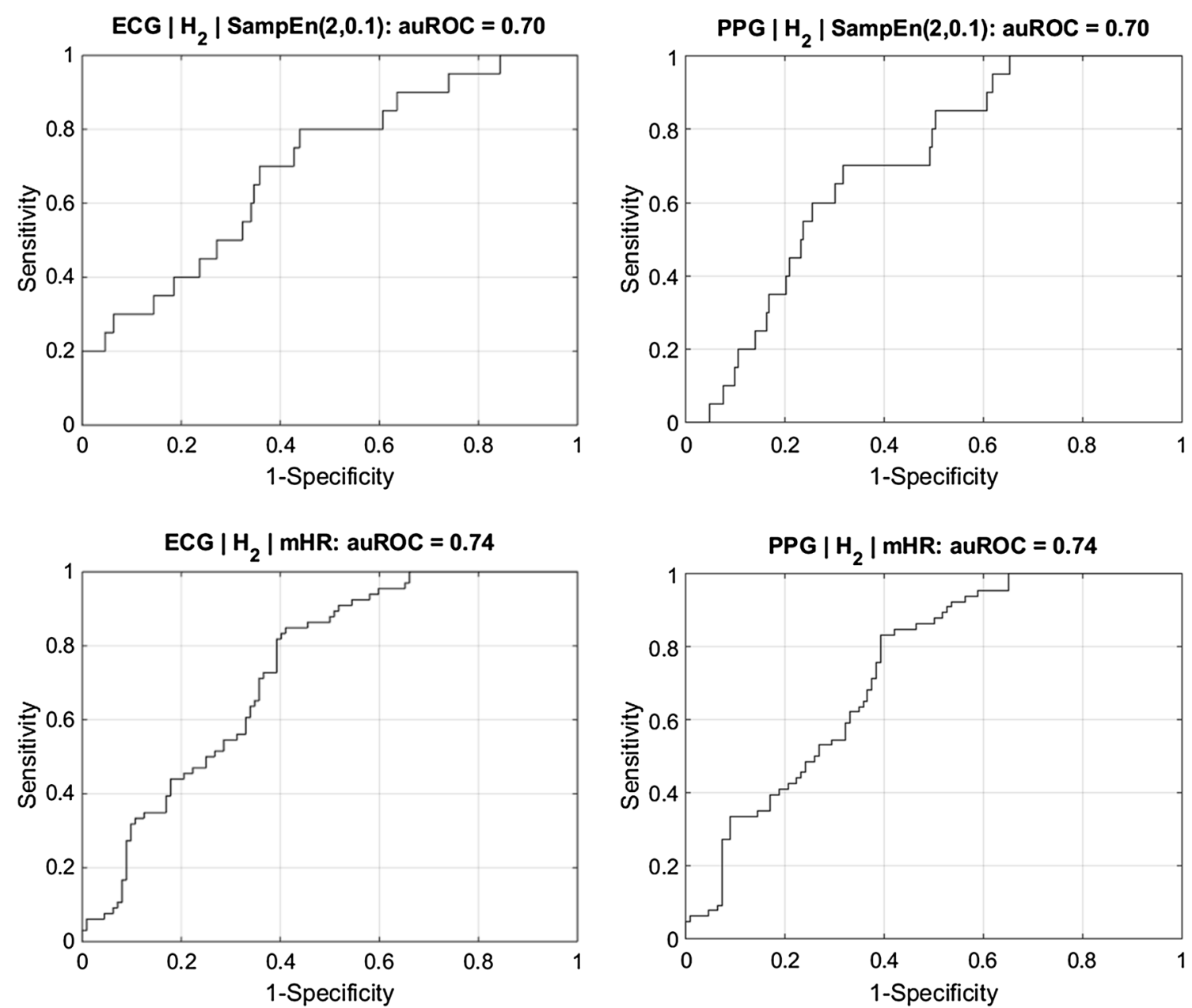

Fig. 4 Receiver operating characteristic curves for the detection of fetal acidemia in $\mathrm{H}_{2}$ (top plots) using SampEn(2,0.1), with ECG (left plot) and PPG (right plot), both associated with an auROC of 0.70 . A similar analysis for the detection of operative delivery is given in the lower plots, for which an auROC of 0.74 was achieved using $\mathrm{mHR}$ in $\mathrm{H}_{2}$

the ECG signal, whereas spectral analysis is commonly used with PPG signals. The narrower shape of the peak in the ECG signal may lead to a higher resolution. Unfortunately, access to the raw PPG signal data was not possible in this study, nor could detailed information on this extraction technique be obtained from the manufacturers. It should be noted that the differences between ECG and PPG signals may also be related to the inherently different nature of these signals: the PPG signal depends on the detection of blood ejected from the heart measuring changes in light absorption, whereas ECG signals evaluate electrical activity of the heart. These two signals should naturally have the same periodicity for healthy subjects, but they can differ in subjects with cardiac dysrhythmias. Patients with atrio-ventricular block or atrial fibrillation can exhibit an electro-mechanical cardiac dysynchrony. While these situations are unlikely to occur in a population of healthy women with uneventful pregnancies, such as the one in the present study, they may appear in higher-risk pregnancies. Bizarre and noisy MHR signals obtained by the ECG are typically associated with the most significant and persistent cardiac disrythmias (Cabaniss 1993).

Progress of labor was associated with an increase of most MHR linear indices and a decrease of entropy indices, with both acquisition methods. This is consistent with a previously described increase in autonomic nervous system activity throughout labor, both from the maternal and fetal sides (Pinto et al. 2014; Gonçalves et al. 2006b). PPG signals seem to be as good as ECG ones for establishing the evolution of slow oscillationbased MHR indices throughout labour.

Similar auROC values were obtained in the discrimination between acidemic and normal fetuses, and between 
normal and vaginal operative deliveries, when using ECG and PPG signals. The highest observed value of 0.70 using SampEn $(2,0.1)$ in $\mathrm{H}_{2}$ regarding fetal acidemia, and of 0.74 using $\mathrm{mHR}$ in $\mathrm{H}_{2}$ in the detection of operative vaginal delivery, opens the possibility of single or combined use of MHR and FHR indices, in the identification of these situations. The discriminatory capacity of these indices may be higher for detection of fetal acidemia when considering a multivariate approach (Gonçalves et al. 2016). However, the objective of maximizing discriminatory performance was not under the scope of the present study.

Further refinement of pre-processing and processing algorithms may optimize the results reported in this study, regarding clinical applications. Conventional fetal monitors supply MHR at $4 \mathrm{~Hz}$ intervals, whereas the frequency bands of interest in human adults are in the range $0-0.4 \mathrm{~Hz}$. Accordingly, $80 \%$ of the spectrum corresponding to the interval between $0.4 \mathrm{~Hz}$ and the Nyquist frequency $(2 \mathrm{~Hz})$ is of little interest. Therefore, signal acquisition or resampling at $2 \mathrm{~Hz}$ rather than $4 \mathrm{~Hz}$ may be considered, as in the present study, and this may allow a reduction in computation time without compromising results. However, particular care must be taken when analyzing MHR signals at other untested sampling frequencies (smaller than $2 \mathrm{~Hz}$ or beat-to-beat), as this has been shown to influence the results of variability indices (Gonçalves et al. 2013). Additionally, the sampling frequency, presence of noise and the filtering procedure of the original signal, and different equipment from the one considered in this study, must be carefully evaluated.

\section{Conclusion}

In conclusion, although PPG capture faster oscillations of the MHR signal less well than ECG and is prone to have higher signal loss in the last 10-min preceding delivery, it can be considered an alternative for MHR monitoring during labour, when appropriate MHR variability indices are used with a proper adaption of cut-off intervals. Further studies are warranted to confirm whether access to the PPG raw signal data or more detailed information on the extraction method will improve performance, and whether linear and entropy analysis of MHR, alone or in combination with FHR, may be clinically useful.

\section{Authors' contributions}

HG performed the signal processing and statistical analysis. PP and MS collected the data. DAC was the main reviewer of the text and JB the main coordinator, concept developer and final text co-reviewer. All authors read and approved the final manuscript.

\footnotetext{
Author details

${ }^{1}$ Center for Health Technology and Services Research (CINTESIS), Faculty of Medicine, University of Porto, Rua Dr Plácido da Costa, s/n, 4200-450 Porto, Portugal. ${ }^{2}$ Department of Obstetrics and Gynecology, Medical School, University of Porto, Porto, Portugal. ${ }^{3}$ Hospital Dr Nélio Mendonça, EPE, Funchal, Portugal. ${ }^{4}$ Department of Obstetrics and Gynecology, São João Hospital,
}

Porto, Portugal. ${ }^{5}$ INEB - Institute of Biomedical Engineering, Porto; 13S - Institute for Research and Innovation in Health, University of Porto, Porto, Portugal. ${ }^{6}$ Hospital Pedro Hispano, Unidade Local de Saúde de Matosinhos, Senhora da Hora, Portugal.

\section{Acknowledgements}

Hernâni Gonçalves is financed by a post-doctoral grant (SFRH/ BPD/69671/2010) from the Fundação para a Ciência e a Tecnologia (FCT), Portugal. This article was supported by FEDER through the operation POCI-010145-FEDER-007746 funded by the Programa Operacional Competitividade e Internacionalização - COMPETE2020 and by National Funds through FCT - Fundação para a Ciência e a Tecnologia within CINTESIS, R\&D Unit (reference UID/IC/4255/2013). Hugo Ferreira and Luis Louro from Speculum, and Criticare Systems Inc., are acknowledged for the support with technical aspects related with signal acquisition.

\section{Competing interests}

Diogo Ayres de Campos and João Bernardes have been involved in the development of Omniview-SisPorto system. Royalties are fully converted to institutional research funds.

Received: 3 February 2016 Accepted: 6 July 2016

Published online: 15 July 2016

\section{References}

Acharya U, Joseph K, Kannathal N, Lim C, Suri J (2006) Heart rate variability: a review. Med Biol Eng Comput 44:1031-1051

Association for the Advancement of Medical Instrumentation (2002) Cardiac monitors, heart rate meters, and alarms. American National Standard (ANSI/AAMI EC13:2002), Arlington

Ayres-de-Campos D, Arulkumaran S, for the FIGO intrapartum fetal monitoring expert consensus panel (2015) Physiology of fetal oxygenation and the main goals of intrapartum fetal monitoring. Int J Gynaecol Obstet 131:5-8

Behar J, Johnson A, Clifford GD, Oster J (2014) A comparison of single channel fetal ECG extraction methods. Ann Biomed Eng 42:1340-1353

Bernardes J, Ayres-de-Campos D (2012) Maternal heart rate analysis during labor. Has the time come for computerized analysis? Acta Obstet Gynecol Scand 91:1474

Cabaniss ML (1993) Fetal monitoring interpretation. Lippincott Williams \& Wilkins, Philadelphia

Costa-Santos C, Antunes L, Souto A, Bernardes J (2010) Assessment of disagreement: a new information-based approach. Ann Epidemiol 20:555-561

Criticare Systems, Inc. (2009) P/N 48127B001, Rev 4. Wuakesha, USA

DiPietro JA, Costigan KA, Gurewitsch ED (2003) Fetal response to induced maternal stress. Early Hum Dev 74:125-138

Dudewicz E, Mishra S (1998) Modern mathematical statistics. Wiley, New York

Gonçalves H, Rocha AP, Ayres-de-Campos D, Bernardes J (2006a) Internal versus external intrapartum foetal heart rate monitoring: effect on linear and nonlinear parameters. Physiol Meas 27:307-319

Gonçalves H, Rocha AP, Ayres-de-Campos D, Bernardes J (2006b) Linear and nonlinear fetal heart rate analysis of normal and acidemic fetuses in the minutes preceding delivery. Med Biol Eng Comput 44:847-855

Gonçalves H, Costa A, Ayres-de-Campos D, Costa-Santos C, Rocha AP, Bernardes J (2013) Comparison of real beat-to-beat signals with commercially available $4 \mathrm{~Hz}$ sampling on the evaluation of foetal heart rate variability. Med Biol Eng Comput 51:665-676

Gonçalves H, Pinto P, Silva M, Ayres-de-Campos D, Bernardes J (2016) Toward the improvement in fetal monitoring during labor with the inclusion of maternal heart rate analysis. Med Biol Eng Comput 54:691-699

Hanson L (2010) Risk management in intrapartum fetal monitoring: accidental recording of the maternal heart rate. J Perinat Neonatal Nurs 24:7-9

Hornero B, Álvarez D, Abásolo D, del Campo F, Zamarrón C (2007) Utility of approximate entropy from overnight pulse oximetry data in the diagnosis of the obstructive sleep apnea syndrome. IEEE Trans Biomed Eng 54:107-113

lyriboz Y, Powers S, Morrow J, Ayers D, Landry G (1991) Accuracy of pulse oximeters in estimating heart rate at rest and during exercise. $\mathrm{Br} J \mathrm{Sp}$ Med 25:162-164 
Kamlin C, Dawson J, O'Donnell C, Morley C, Donath S, Sekhon J, Davis P (2008) Accuracy of pulse oximetry measurement of heart rate of newborn infants in the delivery room. J Pediatr 152:756-760

Kovács L, Tozsér J, Kézér FL, Ruff F, Aubin-Wodala M, Albert E, Choukeir A, Szelényi Z, Szenci O (2015) Heart rate and heart rate variability in multiparous dairy cows with unassisted calvings in the periparturient period. Physiol Behav 139:281-289

Lao HC, Hseu SS, Huang CJ, Chan KH, Kuo CD (2009) The effect of heart rate variability on request for labour epidural analgesia. Anaesthesia 64:856-862

Lu G, Yang F (2009) Limitations of oximetry to measure heart rate variability measures. Cardiovasc Eng 9:119-125

Lu S, Chen X, Kanters JK, Solomon IC, Chon KH (2008) Automatic selection of the threshold value $r$ for approximate entropy. IEEE Trans Biomed Eng 55:1966-1972

Martinez WL, Martinez AR (2002) Computational statistics handbook with MATLAB. CRC Press, Boca Raton

Murray ML (2004) Maternal or fetal heart rate? Avoiding intrapartum misidentification. J Obstet Gynecol Neonatal Nurs 33:93-104

Nagel C, Erber R, Ille N, von Lewinski Aurich J, Möstl E, Aurich C (2014) Parturition in horses is dominated by parasympathetic activity of the autonomous nervous system. Theriogenology 82:160-168

Pincus S (1991) Approximate entropy as a measure of system complexity. Proc Natl Acad Sci USA 88:2297-2301

Pincus S, Viscarello R (1992) Approximate entropy: a regularity measure for fetal heart rate analysis. Obstet Gynecol 79:249-255

Pinto P, Bernardes J, Costa-Santos C, Amorim-Costa C, Silva M, Ayres-de-Campos D (2014) Development and evaluation of an algorithm for computer analysis of maternal heart rate during labor. Comput Biol Med 49:30-35

Puertas A, Navarro M, Velasco P, Montoya F, Miranda JA (2005) Intrapartum fetal pulse oximetry and fetal heart rate decelerations. Int J Gynaecol Obstet 85:12-17
Richman JS, Moorman JR (2000) Physiological time-series analysis using approximate entropy and sample entropy. Am J Physiol Heart Circ Physiol 278:H2039-H2049

Sherman DJ, Frenkel E, Kurzweil Y, Padua A, Arieli S, Bahar M (2002) Characteristics of maternal heart rate patterns during labor and delivery. Obstet Gynecol 99:542-547

Singh J, Kamlin C, Morley C, O'Donnell C, Donath S, Davis P (2008) Accuracy of pulse oximetry in assessing heart rate of infants in the neonatal intensive care unit. J Paediatr Child Health 44:273-275

Söhnchen N, Melzer K, Martinez de Tejada B, Jastrow-Meyer N, Othenin-Girard V, Irion O, Boulvain M, Kayser B (2011) Maternal heart rate changes during labour. Eur J Obstet Gynecol Reprod Biol 158:173-188

STAN Service Manual, Neoventa, Sweden 2005

Sukor JA, Redmond SJ, Lovell NH (2011) Signal quality measures for pulse oximetry through waveform morphology analysis. Physiol Meas 32:369-384

Task force of the European Society of Cardiology, the North American Society of Pacing and Electrophysiology (1996) Heart rate variability_-standards of measurement, physiological interpretation and clinical use. Circulation 17:354-381

Tejera E, Jose Areias M, Rodrigues A, Ramõa A, Manuel Nieto-Villar J, Rebelo I (2011) Artificial neural network for normal, hypertensive, and preeclamptic pregnancy classification using maternal heart rate variability indexes. J Matern Fetal Neonatal Med 24:1147-1151

Van Leeuwen P, Geue D, Thiel M, Cysarz D, Lange S, Romano MC, Wessel N, Kurths J, Grönemeyer DH (2009) Influence of paced maternal breathing on fetal-maternal heart rate coordination. PNAS 106:13661-13666

Weissman A, Torkhov O, Weissman Al, Drugan A (2009) The effects of meperidine and epidural analgesia in labor on maternal heart rate variability. Int J Obst Anesth 18:118-124

Zamarrón C, Romero PV, Gude F, Amaro A, Rodriguez JR (2001) Screening of obstructive sleep apnoea: heart rate spectral analysis of nocturnal pulse oximetric recording. Respir Med 95:759-765

\section{Submit your manuscript to a SpringerOpen ${ }^{\circ}$ journal and benefit from:}

- Convenient online submission

- Rigorous peer review

- Immediate publication on acceptance

- Open access: articles freely available online

- High visibility within the field

- Retaining the copyright to your article

Submit your next manuscript at springeropen.com 